
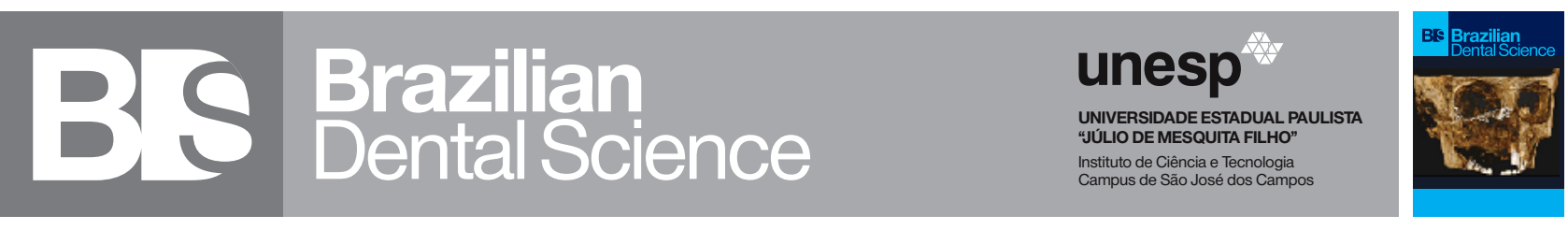

\title{
Evaluation of the bond strength of orthodontic brackets and the degree of polymerisation and microhardness of an orthodontic adhesive using polywave light curing unit and varying light densities
}

Avaliação da resistência de união, grau de polimerização e microdureza de um adesivo para colagem de bráquetes ortodônticos utilizando unidade de polimerização polywave e densidades de luz variáveis.

Nuri Mert TOPBAŞI ${ }^{1}$, Yasin Atakan BENKLI ${ }^{2}$

1 - Biruni University - Faculty of Dentistry - Department of Orthodontics - İstanbul - Turkey.

2 - Ordu University - Faculty of Dentistry - Department of Orthodontics - Ordu - Turkey.

\begin{abstract}
Objective: This study evaluates the shear bond strength (SBS) and Vickers micro-hardness (VHN) of the orthodontic adhesive resin Transbond XT using thermocycled samples. The study also measures the degree of cure by poliwave light curing unit Valo. Materials and Methods: 135 brackets were bonded for the SBS test, and 90 disc-shaped orthodontic adhesive resins were prepared for the VHN test. The measurements were taken either immediately or after 500 or 10.0000 thermocycling. The SBS and VHN test data were statistically evaluated using a Two-way ANOVA and Tukey multiple comparison tests. The degree of conversion (DC) was measured by FTIR. Results: The 10-sec polymerized control group (57.08) and the 10.000 termocycled samples (55.96) had the highest VHN scores. On the other hand, the 3 second polymerized and the 10.000 termocycled samples (39.22) had the lowest VHN scores. There was no significant difference in the bracket SBS values between the termocycled and immediate groups. An evaluation of the bond failure surfaces revealed that the ARI scores did not differ between the immediate and the thermo-cycled groups according to the power modes. The FTIR results revealed that the lowest DC was seen in the 3 second light-cured sample. Conclusion: Transbond XT provided sufficient bond strength, microhardness and DC under in vitro bracket bonding conditions after 3 and $10 \mathrm{~s}$ of Poliwave LED curing. However, low mean values were seen in the groups that received Poliwave LED curing for only $3 \mathrm{~s}$.
\end{abstract}

\section{KEYWORDS}

FTIR; Light-Emitting Diode; Orthodontics; Thermocycling.

\section{RESUMO}

Objetivo: Este estudo avalia a resistência ao cisalhamento (SBS) e a microdureza Vickers (VHN) da resina adesiva ortodôntica Transbond XT utilizando amostras termocicladas. $\mathrm{O}$ estudo também mede o grau de cura pela unidade de fotopolimerização Valo poliwave. Materiais e Métodos: 135 braquetes foram colados para o teste SBS e 90 discos de resina adesiva ortodôntica foram preparados para o teste VHN. As medições foram feitas imediatamente ou após 500 ou 10.000 ciclos de termociclagem. Os dados dos testes SBS e VHN foram avaliados estatisticamente usando ANOVA 2 fatores e teste de comparação múltipla de Tukey. O grau de conversão (DC) foi medido por FTIR. Resultados: O grupo controle polimerizado por 10 segundos $(57,08)$ ciclados por 10.000 ciclos $(55,96)$ tiveram os valores VHN mais altos. Por outro lado, as amostras polimerizadas de 3 segundos e 10.000 ciclos $(39,22)$ os valores de VHN mais baixos. Não houve diferença significativa nos valores de SBS do braquete entre os grupos termociclados e imediato. Uma avaliação das superfícies de falha de adesão revelou que os escores do ARI não diferiram entre os grupos imediato e termociclados de acordo com as densidades de potência. Os resultados do FTIR revelaram que o menor DC foi observado nas amostras fotopolimerizadas de 3 segundos. Conclusão: Transbond XT forneceu suficiente resistência de união, microdureza e DC sob condições de colagem de braquetes in vitro após 3 e $10 \mathrm{~s}$ de polimerização em LED Poliwave. No entanto, valores médios baixos foram observados nos grupos que receberam a cura do LED Poliwave por apenas $3 \mathrm{~s}$.

\section{PALAVRAS-CHAVE}

FTIR; Diodo emissor de luz; Ortodontia; Termociclagem. 


\section{INTRODUCTION}

B racket debonding is a clinically undesired occurrence for both the clinician and the patient. It results in an increase in treatment costs and duration. Once enamel surfaces are exposed to acid etching bond strength decreases due to the re-bonding [1]. The age and gender of the patient, the treatment mechanics, and the orthodontist have all been shown to affect bracket-debonding rates $[2,3]$. Once the adhesive used to attach the bracket to the dental surface is sufficiently cured, it does neither become significantly harder nor change form. Adhesion strength is influenced by many factors, including: the light device used, the amount of time the adhesive is exposed to the polymerizing light, the type of acid used for the enamel surface etching, the length of the adhesive's application, the acid concentration in the oral cavity, the composition of the adhesive, the shape of the bracket base, the bracket material (metallic or ceramic), the type of tooth, and whether or not the tooth received fluorid treatment before adhesion [4-6].

Polymerization is used to harden and strengthen the adhesive that bonds the brackets to the teeth. The DC is directly related to the amount of energy absorbed by the adhesive, which, in turn, depends on the light density and how long the adhesive is exposed to the light. The greater the total light energy is the greater the brackets bond strength [7]. High density light is preferred because it can convey the necessary amount of light energy to the adhesive quicker. The light-curing devices with increased emission capacity and shorter radiation times have recently been developed to facilitate bracket adhesion [8]. The curing technology is based on the use of photo-activitate systems that absorb irradiation from the light curing units at a specific wavelength. This in turn allows a higher DC that determines the final properties of the restoration. In order to have a successful resin based composite polymerization, the spectral emission of the light-curing unit needs to be matched with the requirements of the photoinitiator system to convert the monomers into a polymer network [9]. Because of its reduced photoinitiator concentration, the average degree of conversion is lower compared to the corresponding formulations with standard photoinitiator concentration. Therefore, photoinitiator concentration plays a vital role in the degree of conversion of the hydrophilic-rich phase [10]. Moreover, The DC is also dependent on the material composition, and other factors such as shade and translucency [11].

Our study evaluates whether these lightcuring devices can provide adequate resistance to orthodontic forces resulting in clinically suitable adhesives. This study measures the shear bond strength (SBS), the DC and the Vickers's Microhardness (VHN) of an orthodontic adhesive that was polymerized with three modes of a LED of the same brand after using thermocycling to age the teeth.

We sought to identify a LED with the shortest effective polymerization time, a feature that would benefit both the dentist and the patient in terms of reducing the length of treatment and improving patient comfort.

The null hypothesizes we tested were: "1) shear bond strength of bracket adhesive to enamel will not be influenced by aging in all polymerization modes. 2) The degree of conversion and micro-hardness of the orthodontic resin will not be influenced by aging and the polymerization protocols.

\section{MATERIAL AND METHODS}

\section{Shear Bond Strength Test (SBS)}

This study obtained 135 non-carious human premolars that had been extracted for orthodontic indications. This in- vitro study has been approved by the appropriate ethics committee (Marmara University Faculty of Dentistry Ethics Comitee approval no. 2016-63). Teeth with cracks, hypo plastic areas or gross structural abnormalities in the enamel were excluded from the study. The teeth were stored in a solution of $0.5 \%$ Chloramine-T $(\mathrm{pH} 9.0)$ at room temperature. The teeth were mounted on standard acrylic blocks (made from 
cylindrical shape silicon molds with diameter of $10 \mathrm{~mm} \times 10 \mathrm{~mm}$.), evenly spaced and randomly divided into 9 groups of 15 teeth each (Table I). The characteristics of the adhesive materials and the light-curing units used in this study are shown in Table II.

Table I - Classification of the groups used in this study.

\begin{tabular}{|c|c|c|c|c|}
\hline Groups & Mode & Time (s) & $\begin{array}{l}\text { Output } \\
\text { (mw/cm²) }\end{array}$ & Storage Condition \\
\hline 1 & \multirow{3}{*}{ Standard } & \multirow{3}{*}{10} & \multirow{3}{*}{1000} & $24 \mathrm{~h} / 37^{\circ} \mathrm{C}$ \\
\hline 2 & & & & 500 termocycled \\
\hline 3 & & & & 10,000 termocycled \\
\hline 4 & \multirow{3}{*}{$\begin{array}{l}\text { High } \\
\text { Power }\end{array}$} & \multirow{3}{*}{8} & \multirow{3}{*}{1400} & $24 \mathrm{~h} / 37^{\circ} \mathrm{C}$ \\
\hline 5 & & & & 500 termocycled \\
\hline 6 & & & & 10,000 termocycled \\
\hline 7 & \multirow{3}{*}{$\begin{array}{l}\text { Xtra High } \\
\text { Power }\end{array}$} & \multirow{3}{*}{3} & \multirow{3}{*}{3200} & $24 \mathrm{~h} / 37^{\circ} \mathrm{C}$ \\
\hline 8 & & & & 500 termocycled \\
\hline 9 & & & & 10,000 termocycled \\
\hline
\end{tabular}

Table II - Characteristics of Adhesive material and Light Curing Unit used in this study.

\begin{tabular}{|c|c|c|c|}
\hline $\begin{array}{l}\text { Adhesive } \\
\text { Material }\end{array}$ & Type & Manufacturer & Composition \\
\hline $\begin{array}{c}\text { Transbond } \\
\text { XT }\end{array}$ & Light-cure & 3M Unitek, USA & $\begin{array}{c}\text { 35\% phosphoric acid } \\
\text { silane-treated quartz, } \\
\text { bisphenol A diglycidyl ether } \\
\text { dimethacrylate, } \\
\text { bisphenol A bis-(2-hydroxye- } \\
\text { thyl)-ether dimethacrylate, } \\
\text { silane-treated silica }\end{array}$ \\
\hline Valo & $\begin{array}{l}\text { Light } \\
\text { Emitting } \\
\text { Diode }\end{array}$ & $\begin{array}{l}\text { Ultradent Pro- } \\
\text { ducts, Inc. SLC, } \\
\text { Utah }\end{array}$ & $\begin{array}{l}\text { The VALO Cordless curing } \\
\text { light uses a custom, multi- } \\
\text {-wavelength ( } 395 \text { - 480nm) } \\
\text { LightEmitting Diode (LED) for } \\
\text { producing the high intensity } \\
\text { light capable of polymerizing } \\
\text { all light cure dental materials. }\end{array}$ \\
\hline
\end{tabular}

Before bonding, the buccal surfaces of the teeth were cleaned and polished with fluoridefree pumice using a rubber-polishing cup. The teeth were thoroughly rinsed with water for 10 $\mathrm{s}$ and dried with an oil-free air stream for $5 \mathrm{~s}$ (Plenmeca Dental Care Units, Finland). Each tooth was etched with an ortho-phosphoric acid gel (35\% phosphoric acid, 3M ESPE, USA) for $30 \mathrm{~s}$, rinsed for $20 \mathrm{~s}$ and dried. Later, each tooth was evaluated for a characteristic dull white, which is a frosted appearance before bracket placement.

In all the groups, the brackets were bonded (bond reliance according to the manufacturer's recommendations for Transbond XT (3M Unitek, USA). The Transbond XT Primer (3M Unitek, USA) was applied to the tooth, thinned with a gentle stream of air and cured according to manufacturer's guidelines. The brackets (Mini Master, American Orthodontics Corporation, USA) were then positioned on each tooth and pressed firmly into place. Later the excess adhesive was removed with an explorer and cured. Each of the LED curing modes (standard, high and extra power) was used to cure the brackets (Mini Master, American Orthodontics Corporation, USA) from the mesial and distal surfaces.

The VALO Cordless (Ultradent Products, Inc. SLC, Utah) curing light uses a custom, multiwavelength (395 - 480nm) Light Emitting Diode (LED) in order to produce a high intensity light capable of polymerizing all light cure dental materials.

After bonding, the teeth in the $24 \mathrm{~h}$ test groups (the immediate groups) (Group-1, Group-4 and Group-7) were stored in distilled water for $24 \mathrm{~h}$ before the SBS test. For the thermocycled groups (Group-2, Group-3, Group-5, Group-6, Group-8 and Group-9), the thermocycles were applied using a thermocycling machine (Esetron, Ankara, Turkey) for 500 cycles (Group-2, Group 5 and Group 8) and for 10,000 cycles (Group-3, Group-6, and Group-9) at $5^{\circ} \mathrm{C}$ and $55^{\circ} \mathrm{C}$ with $30 \mathrm{~s}$ dwell times.

The SBS of the samples were measured using an instron (Shimatsu AGS-1000kGW, Shimadzu Corp., KYOTO, Japan) instrument with a cross-head speed of $0.5 \mathrm{~mm} / \mathrm{min}$ and 1 $\mathrm{KN}$ load cell. The force to remove the brackets were measured in Newtons $(\mathrm{N})$, and the SBS values were calculated by converting Newtons into Megapascals (MPa) using the Trapezium X (Shimadzu Corp., Kyoto, Japan).

After the debonding procedure, the buccal surfaces of the teeth and the metallic 
brackets were analyzed with a stereomicroscope (Leica M27.5, Heerbrugg, Switzerland) at a magnification of 40x. The location of the adhesive failure was determined using a modified adhesive remnant index (ARI) with scoring criteria according to Bishara and Trubue [12].

$1=$ All resin stays on enamel

$2=$ More than $90 \%$ resins stay on enamel

$3=10-90 \%$ resin stays on enamel

$4=$ Less than $10 \%$ resin stays on enamel

$5=$ No resin observed on enamel

\section{Microhardness Test}

Sets of 90 adhesive resin discs were made using a plastic mold that was $5.5 \mathrm{~mm}$ in diameter and $2 \mathrm{~mm}$ in height. After the resin was placed in the mold, both surfaces were covered with glass slides, and light-cured according to the manufacturer's guidelines for 10,8 or $3 \mathrm{~s}$. The VHN of the adhesives was evaluated with a micro-hardness tester (Wilson Wolpert MicroVickers 401MVD, Germany). A 2.942 N load was applied to the adhesive discs for $10 \mathrm{~s}$, and the scores were recorded in units of hardness Vickers (HV). Three evaluations were made on the cured side of the samples. The samples were tested after $24 \mathrm{~h}$ in the immediate group and after 500 and 10.000 cycles in the thermocycled groups.

\section{Degree of Conversion}

Fourier-transform infrared (FTIR) spectroscopy was used to assess the degree of adhesive polymerization, also referred to as of DC. Uncured Transbond XT was used for the internal standard analytic frequency. An area under the peak, created with the spectra tangent baseline method, indicated stretching of the methacrylate aliphatic carbon-carbon double bond at $(1638 \mathrm{~cm} \mathrm{-1)}$. The aromatic carbon-carbon bonds, with stretching vibrations at (1608 cm-1), were not affected by the polymerization reaction and were selected as two internal standard reference frequencies. Totally 15 samples were tested for 3 different curing modes ( $\mathrm{n}=5$ for each curing modes).

By utilizing the change in ratio of the aliphatic $\mathrm{C}=\mathrm{C}$ before and after curing, the degree of conversion of the aliphatic $\mathrm{C}=\mathrm{C}$ into $\mathrm{C}-\mathrm{C}$ could be calculated using the following formula:

\%Conversion $=100 \times 1-\frac{\operatorname{Polymer}(\mathrm{C}=\mathrm{C}) \times \operatorname{monomer}(\mathrm{C}-\mathrm{C})}{\operatorname{Monomer}(\mathrm{C}=\mathrm{C}) \times \operatorname{polymer}(\mathrm{C}-\mathrm{C})}$

\section{Statistical Analysis}

The statistical analysis was performed using the SPSS version 22.0 for Windows software (SPSS Inc., Chicago, IL, USA). The data was presented as the number of cases and percentage (\%) of the categorical variables (in both the thermocycle applications and the control groups). The data (SBS and VHN) was presented in a sample size (n), with a mean, standard deviation, and a minimum and maximum for the thermocycle applications $(0$, 500 and 10,000) according to the curing times (3, 8 and $10 \mathrm{~s})$.

The two-way ANOVA was used to compare the SBS for the thermocycle groups and the curing times, according to the results of the Levene test and the Shapiro Wilk test which test for the equality of variance and the normality assumption, respectively ( $\mathrm{p}>0,05)$. Then, the Tukey HSD multiple comparison test was applied to determine any further differences among the groups. A P-value of less than 0.05 was considered to indicate a statistically significant result. The relation between SBS and ARI scores was determined by One-way Anova and ki-squre test $(\mathrm{p}<0.05)$.

\section{RESULTS}

\section{SBS Values}

In this study, the curing time had a statistically significant effect on the SBS of the Transbond XT adhesive $(\mathrm{P}<0.001)$. No statistically significant differences were found between the number of thermo-cycles and the curing time in the thermo-cycled groups $(\mathrm{P}>$ 0.05). 
The SBS of the adhesive (Transbond XT) was statistically lower for the samples that received only $3 \mathrm{~s}$ of curing time compared to those that received 8 or $10 \mathrm{~s}$. This was true in all groups, including the immediate and termocycled (500 and 10,000) groups ( $<$ < $0.01)$. The lowest SBS values $(13.16 \pm 3.27)$ were found in the samples that received 10.000 termocycled and $3 \mathrm{~s}$ of curing time (Table III).

Table III - SBS values (MPa) of all groups (Avarage \pm Standard Deviation).

\begin{tabular}{|c|c|c|c|c|}
\hline \multirow{2}{*}{ Termocycle } & \multicolumn{3}{|c|}{ Time (sec) } & \multirow{2}{*}{$\begin{array}{l}\text { General } \\
\text { avarage }\end{array}$} \\
\hline & 3 & 8 & 10 & \\
\hline 0 & $17,68 \pm 8,99$ & $20,65 \pm 7,77$ & $23,45 \pm 5,94$ & $20,59 \pm 7,86$ \\
\hline 500 & $15,95 \pm 5,34$ & $20,80 \pm 7,38$ & $21,52 \pm 7,43$ & $19,42 \pm 7,09$ \\
\hline 10000 & $13,16 \pm 3,27$ & $19,69 \pm 5,01$ & $21,59 \pm 6,94$ & $18,15 \pm 6,33$ \\
\hline $\begin{array}{l}\text { General } \\
\text { avarage }\end{array}$ & $15,60 \pm 6,46 b$ & $20,38 \pm 6,69 a$ & $22,18 \pm 6,70 a$ & $19,39 \pm 7,14$ \\
\hline
\end{tabular}

The comparison of SBS values according to time and aging are shown in Table 4. Polymerization time has no significant effect on SBS values of the resin in immediate and $500 \mathrm{TC}$ groups. On the other hand; 10,000 TC aging had a significant difference between SBS values of 3,8 and 10 second polymerized groups. (Table IV).

Table IV - Comparison of SBS values (MPa) according to time and aging.

\begin{tabular}{|ccccc|}
\hline SBS & $\mathbf{3 s n}$ & $\mathbf{8 s n}$ & $\mathbf{1 0}$ sn & pł \\
\hline Immediate & $17,68 \pm 8,99$ & $20,65 \pm 7,77$ & $23,45 \pm 5,94$ & 0,133 \\
\hline 500 TC & $15,95 \pm 5,34$ & $20,8 \pm 7,38$ & $21,52 \pm 7,43$ & 0,062 \\
\hline $\mathbf{1 0 . 0 0 0}$ TC & $13,16 \pm 3,27$ & $19,69 \pm 5,01$ & $21,59 \pm 6,94$ & $\mathbf{0 , 0 0 0 1}$ \\
\hline $\mathbf{p}^{*}$ & 0,155 & 0,891 & 0,681 & \\
\hline
\end{tabular}

‡ Matched One Way Analysis of Variance * One Way Analysis of Variance

ARI scores are shown in Table 5. A statistically significant difference was found in the ARI score distribution in immediate groups of 3-8-10 s. In addition, there is a significant difference in ARI score distribution between immediate, 500and 10,000 TC groups (Table V).
Table V - ARI Scores.

\begin{tabular}{|c|c|c|c|c|c|c|c|c|}
\hline \multicolumn{9}{|c|}{ Termo cyle(TC) } \\
\hline & & & & mediate & & $500 \mathrm{TC}$ & $10.000 \mathrm{TC}$ & $p+$ \\
\hline \multirow{12}{*}{$\begin{array}{c}\text { Time } \\
\text { (T) }\end{array}$} & \multirow{4}{*}{$3 \mathrm{sn}$} & ARI2 & 6 & $40,00 \%$ & 0 & $0,00 \%$ & $0,00 \%$ & \\
\hline & & ARI3 & 0 & $0,00 \%$ & 8 & $53,30 \%$ & $6,70 \%$ & \\
\hline & & ARI4 & 6 & $40,00 \%$ & 3 & $20,00 \%$ & $853,30 \%$ & \\
\hline & & ARI5 & 3 & $20,00 \%$ & 4 & $26,70 \%$ & $640,00 \%$ & 0,0001 \\
\hline & \multirow{4}{*}{$8 \mathrm{sn}$} & ARI2 & 3 & $20,00 \%$ & 0 & $0,00 \%$ & $2 \quad 13,30 \%$ & \\
\hline & & ARI3 & 3 & $20,00 \%$ & 3 & $20,00 \%$ & $6,70 \%$ & \\
\hline & & ARI 4 & 5 & $33,30 \%$ & 6 & $40,00 \%$ & $6 \quad 40,00 \%$ & \\
\hline & & ARI5 & 4 & $26,70 \%$ & 6 & $40,00 \%$ & $640,00 \%$ & 0,601 \\
\hline & \multirow{5}{*}{$10 \mathrm{sn}$} & ARI2 & 0 & $0,00 \%$ & 0 & $0,00 \%$ & $6,70 \%$ & \\
\hline & & ARI3 & 3 & $20,00 \%$ & 3 & $20,00 \%$ & $0,00 \%$ & \\
\hline & & ARI 4 & 3 & $20,00 \%$ & 9 & $60,00 \%$ & $960,00 \%$ & \\
\hline & & ARI5 & 9 & $60,00 \%$ & 3 & $20,00 \%$ & $5 \quad 33,30 \%$ & 0,068 \\
\hline & & $p+$ & & 0,031 & & 0,105 & 0,714 & \\
\hline
\end{tabular}

ÜKi Squre Test

No relation was found between SBS values and ARI scores in this in-vitro study (Table 6).

Table VI - Relation between SBS values and ARI scores.

\begin{tabular}{|cc|}
\hline \multicolumn{2}{|c|}{ SBS } \\
\hline ARI2 & $18,81 \pm 7,89$ \\
\hline ARI3 & $18,88 \pm 8,2$ \\
\hline ARI4 & $18,96 \pm 7,11$ \\
\hline ARI5 & $20,29 \pm 6,57$ \\
\hline ** & 0,773 \\
\hline
\end{tabular}

*One -way Anova

\section{Microhardness}

The statistical relationships between the curing time and the thermo-cycle applications indicated that these factors significantly influenced the hardness of the Transbond XT adhesive $(\mathrm{p}=0.005)$ (Table VII). 
Table VII - Interaction of Vickers Micro-hardness of different thermocycled and curing time (Avarage \pm Standard Deviation)

\begin{tabular}{|c|c|c|c|c|}
\hline \multirow{2}{*}{ Termocycle } & \multicolumn{3}{|c|}{ Time (sec) } & \multirow{2}{*}{$\begin{array}{l}\text { General } \\
\text { avarage }\end{array}$} \\
\hline & 3 & 8 & 10 & \\
\hline 0 & $\begin{array}{c}49,91 \pm 7,94 \\
\text { bcd }\end{array}$ & $\begin{array}{c}54,30 \pm 4,14 \\
a b c\end{array}$ & $\begin{array}{c}57,08 \pm 2,67 \\
a\end{array}$ & $\begin{array}{c}53,76 \pm 6,01 \\
A\end{array}$ \\
\hline 500 & $\begin{array}{c}47,02 \pm 4,61 \\
\text { b }\end{array}$ & $\begin{array}{c}51,43 \pm 2,21 \\
\text { a-d }\end{array}$ & $\begin{array}{c}55,72 \pm 1,95 \\
a b\end{array}$ & $\begin{array}{c}51,39 \pm 4,73 \\
A\end{array}$ \\
\hline 10000 & $\begin{array}{c}39,22 \pm 2,95 \\
e\end{array}$ & $\begin{array}{c}49,57 \pm 2,29 \\
c d\end{array}$ & $\begin{array}{c}55,96 \pm 4,96 \\
a\end{array}$ & $\begin{array}{c}48,25 \pm 7,82 \\
B\end{array}$ \\
\hline $\begin{array}{l}\text { General } \\
\text { avarage }\end{array}$ & $\begin{array}{c}45,38 \pm 7,07 \\
\text { C }\end{array}$ & $\begin{array}{c}51,77 \pm 3,52 \\
B\end{array}$ & $\begin{array}{c}56,25 \pm 3,38 \\
A\end{array}$ & $51,13 \pm 6,64$ \\
\hline
\end{tabular}

$\mathrm{a}, \mathrm{b}$ means the application groups and difference between curing times

Tukey HSD multiple comparison test

Although thermo cycling resulted in decreased SBS values across all groups, the decrease was statistically significant for the groups that received only $3 \mathrm{~s}$ of curing. In general, the $3 \mathrm{~s}$ cured samples had lower VHN values, while the $10 \mathrm{~s}$ cured samples had higher VHN values. The highest VHN values were obtained in the 10-second cured samples of the immediate group (57.08); and the lowest VHN values were found in the $3 \mathrm{~s}$ cured samples of the 10,000-termocycled group (39.22).

\section{Degree of Conversion}

The VALO curing unit, when used in the 8 $\mathrm{s}$ high-power mode, produced the highest DC\% (58.12), with no statistically significant difference being found between that and the $10 \mathrm{~s}$ standard mode (52.45\%). The lowest DC\% was found in the $3 \mathrm{~s}$ extra-high-power mode (38.14), whereas significant differences were found between the 8 $\mathrm{s}$ and $10 \mathrm{~s}$ curing modes (Figure 1 ).

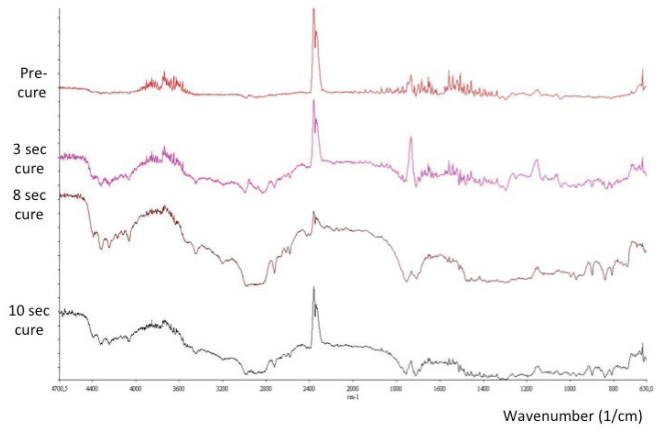

Figure 1 - Superimposed FTIR spectra of the Transbond XT adhesive both with (3, 8 and 10 second light cure) and without light curing.

\section{DISCUSSION}

Depending on the light power and radiation time, the mean SBS values of the adhesive used in our study was as high as $20.59 \pm 7,86 \mathrm{MPa}$. Reynolds advised that brackets should be bonded to enamel surfaces at a minimum of 6-8 MPa and that any lesser bonding values would be clinically unacceptable [13]. Reviewing the literature, we identified several studies reporting Transbond XT bonding values. Ozturk et al. [14] found the bond strength of Transbond XT to be $25.6 \pm 3.9$ $\mathrm{MPa}$, Sfondrini et al. [15] found it to be $24.1 \pm$ $5.5 \mathrm{MPa}$ and Webster et al. [16] found it to be $26.88 \pm 6.89 \mathrm{MPa}$.

In a study investigating the clinical and in vitro bond strengths of metal brackets cured with varying LED devices and polymerization times, $\mathrm{Oz}$ et al. [17] reported that both 10-second Elipar LEDs (3M ESPE, USA) and 3-second VALO LEDs (Ultradent Product Inc, SLC, Utah) could be used to clinically bond brackets. Swanson et al. [6] found that brackets polymerized with three different LED and halogen light devices had bond strengths of over $8 \mathrm{MPa}$, even after only $10 \mathrm{~s}$ of radiation; the highest bond value was obtained with the UltraLume-LED2 (Ultradent Product Inc, SLC, Utah) after $40 \mathrm{~s}$ of radiation (12.3 MPa).

Usumez et al. (2004) [18] reported that an LED light source with a power density of 400 $\mathrm{mw} / \mathrm{cm}^{2}$ and curing times of $20 \mathrm{~s}(13.964 .8 \mathrm{MPa})$ and $40 \mathrm{~s}$ (12.7 $65.1 \mathrm{MPa})$ achieved adequate bond strength in clinical settings; however, 10 s (9.1 $63.1 \mathrm{MPa})$ of radiation did not produce the desired efficacy. In contrast, we found that radiation from a LED light source for $10 \mathrm{~s}(22,18$ $\pm 6,70$ ) yielded sufficient bond strength. The difference in these results can likely be explained by the weaker light source used in the study.

Several studies were already carried out to investigate the possible impact of different etching procedures, adhesive materials, light cure devices and curing times on SBS and DC [19-21].

Faria et al. concluded that the curing modes of the LED light-curing unit had significant effects on the total energy available to light-activate the 
composite, whereas the differences observed on energy delivered only minimally affected the DC of the composite used to bond metal orthodontic brackets [22].

Cerekja and Cakirer measured the bond strengths of metal brackets after radiation with high power halogen and LED light devices, both before and after thermocycling treatments. They did not find any significant difference in the bond strength before or after the thermocycling applications. Cerekja and Cakirer also reported that the adhesive radiation time could be reduced by $6 \mathrm{~s}$ with a high-power halogen light device and by $10 \mathrm{~s}$ with an LED device [23]. Our study obtained similar results. In general, there was no statistically significant difference in the bracket bond strength between the samples that were and were not subjected to thermocycling. While we did find significant bond strength differences between the groups that received 10,000 thermocycling and 8 and $10 \mathrm{~s}$ of radiation compared to those that received $3 \mathrm{~s}$ of radiation ( $\mathrm{P}$ $<0.01$ ), the SBS values in the 3 -second radiation group were still clinically acceptable for bracket adhesion in orthodontic applications. So, the first null hypothesis was rejected.

Although an ARI score reflects a subjective assessment, it is an important index to classify the amount of adhesive that remains on the tooth surface after bracket debonding and to determine the percentage of the debonding area [24]. We found that the ARI scores did not differ between the control group and the experimental group with respect to light-curing duration in 8 and 10 $\mathrm{s}$. But in the $3 \mathrm{~s}$ group, there is a difference in distribution of the ARI Scores. Meanwhile, there was no significant relation between the SBS values and the ARI scores in any of the groups.

Shin DH et al. [25] found the DC of the Transbond XT adhesive to be 54.7, a value similar to that found in our study. High light energy may accelerate polymerization contraction forces, which, in turn, may lead to destructive contraction stresses on the orthodontic brackets. The primary factors affecting bracket bond strength are contraction stresses associated with polymerization and the mechanical weaknesses of the under-polymerized resin [26]. In our study, the pre-polymerization absorbance values of the Transbond XT adhesive after radiation for 10,8 and $3 \mathrm{~s}$ were observed in a narrow spectrum (a $1600-1700$ band). These band measurements were inserted into the appropriate formula, and the corresponding degrees of transformation were calculated. Based on the 1638 band of the control sample, the percent polymerization was $52.45 \%$ after $10 \mathrm{~s}$ of radiation at $1000 \mathrm{mw} /$ $\mathrm{cm}^{2}$ of light power, $58.12 \%$ after $8 \mathrm{~s}$ of radiation at $1400 \mathrm{mw} / \mathrm{cm}^{2}$ of light power and $38.14 \%$ after $3 \mathrm{~s}$ of radiation at $3200 \mathrm{mw} / \mathrm{cm}^{2}$ of light power. Using the 1638 band measurement, the DC values were the lowest for the samples that received $3 \mathrm{~s}$ of radiation, and the DC values obtained after $8 \mathrm{~s}$ of radiation were slightly higher than those obtained after $10 \mathrm{~s}$ of radiation. The polymerization rate increased with increasing DC percentages. As seen in the FTIR results, this lower bond strength may be due to the higher number of residual monomers in the adhesive groups that were polymerized for $3 \mathrm{~s}$.

The rate of propagation for polymerization is proportional to the monomer radicals, and the formation of monomer radicals is dependent on the rate of generation of the initiator radicals. On the other hand, the polymerization of the hydrophilic-rich phase shows how the variable light intensity could impact the hydrophilicrich phase. The light intensity will vary along the length and breadth of the hybrid layer [27]. Lovell et al. showed a power law relation between the rate of polymerization and light intensity of the BisGMA/TEGDMA system.20 Increasing light intensity enhances radical generation, which in turn enhances the rate of polymerization [28].

Cerveira et al. [29] found in their study that the hardness values of the Transbond XT resin was between $20-25 \mathrm{VHN}$ with a halogen light device and between 18-21VHN with a LED light device. Albert $\mathrm{H}$ [30] reported that the use of high power light sources for short curing times negatively affects polymerization by increasing the formation of free radicals. They argued that increased radiation times reduced the 
formation of free radicals. Similar to the Albert H. results, our study showed that the VHN values increased when the radiation duration increased in both the control groups and in the groups that were subject to thermocycling. In contrast, Souza [31] observed no changes in adhesive mechanical properties after the application of 5000 thermocycling. This contradiction may be due to the use of different adhesive materials. According to our study, the low VHN value in the group that was subjected to $10,000 \mathrm{TC}$ can be explained by the higher amount of water that is present in the adhesive at higher numbers of thermocycling. This is also due to the increasing number of residual monomers in the adhesives that received 3-second radiations, as well as the decreasing bond values due to the negative effects of thermal expansion on the adhesive.

The second null hypothesis tested was rejected. We found that the degree of conversion and micro-hardness of the orthodontic resin was influenced by aging and that all the SBS values were decreased. The polymerization protocols including time and mode affected the results of SBS, micro-hardness and DC tests.

Although this experimental study gave information about the bond strength of brackets, the findings based on the present in-vitro set ting, do not fully reflect the real situation in the oral cavity and mimic the patient-related clinical conditions such as saliva, beverage habits, oral hygiene and side-effects of medications.

Further studies demonstrating both in-vitro and real oral conditions are needed to confirm these results.

\section{CONCLUSION}

Within the limitations of this study; the Poliwave-LED Valo achieved sufficient bond strength, micro-hardness and DC values in bracket adhesion with Transbond XT using all modes including 10s $\left(1000 \mathrm{mw} / \mathrm{cm}^{2}\right)$, 8s $(1400 \mathrm{mw} /$ $\left.\mathrm{cm}^{2}\right)$ and $3 \mathrm{~s}\left(3200 \mathrm{mw} / \mathrm{cm}^{2}\right)$ of polymerization under in vitro conditions. However, the bracket bond strength was found to be low in the group that was subjected to 10,000-thermo cycling and
$3 \mathrm{~s}$ of polymerization with the $3200 \mathrm{mw} / \mathrm{cm}^{2}$ light intensity.

Acknowledgement: Ordu University Scientific Research Project Unit supported this study and research project number was BU-1701.

\section{REFERENCES}

1. Kachoei M, Mohammadi A, Esmaili Moghaddam M, RikhtegaranS, Pourghaznein M, Shirazi S. Comparison of multiple rebond shear strengths of debonded brackets after preparation with sandblasting and C02 laser. JDent Res Dent Clin DentProspects. 2016;10(3):148-54. doi:10.15171/joddd.2016.024

2. Silta YT,Dunn WJ, Peters CB. Effect of shorter polymerization times when using the latest generation of light-emitting diodes. Am J Orthod Dentofacial Orthop. 2005;128(6):744-8. doi:10.1016/j.ajodo.2004.09.029

3. Gronberg K, Rossouw PE, Miller BH, Buschang P.Distance and time effect on shear bond strength of brackets cured with a second-generation light-emitting diode unit. Angle Orthod. 2006;76(4):682-8. doi:10.1043/00033219(2006)076[0682:DATEOS]2.0.C0;2

4. Arnold RW, Combe EC, Warford JH Jr. Bonding of stainless steel brackets to enamel with a new self-etching primer. Am J Orthod Dentofacial Orthop. 2002;122(3):274-6. doi:10.1067/mod.2002.125712

5. Mandall NA, MillettDT, Mattick CR, Hickman J, Worthington HV, Macfarlane TV. Orthodontic adhesives: a systematic review. J Orthod. 2002;29(3):205-195. doi:10.1093/ortho/29.3.205

6. Swanson T, Dunn WJ, Childers DE, Taloumis LJ. Shear bond strength of orthodontic brackets bonded with light-emitting diode curing units at various polymerization times. Am J Orthod Dentofacial Orthop. 2004;125(3):337-41. doi:10.1016/j.ajodo.2003.04.011

7. Sfondrini MF,Cacciafesta V,Scribante A, Klersy C. Plasma arc versus halogen light curing of orthodontic brackets: a 12-month clinical study of bond failures. Am J Orthod Dentofacial Orthop. 2004;125(3):342-7. doi:101016/j. ajod0.2003.02.008

8. Cacciafesta V,Sfondrini MF, Sfondrini G. A xenon arc light-curing unit for bonding and bleaching. J Clin Orthod. 2000;34(2):94-6.

9. Segreto DR, Naufel FS, Brandt WC, Guiraldo RD, Correr-Sobrinho L, Sinhoreti MA. Influence of photoinitiator and light-curing source on bond strength of experimental resin cements to dentin. Braz Dent J. 2016;27(1):83-9. doi:10.1590/0103-6440201600387

10. Abedin F, YeQ, Parthasarathy R, Misra A, Spencer P.Polymerization behavior of hydrophilic-rich phase of dentin adhesive. J Dent Res. 2015;94(3):500-7. doi:101177/0022034514565646

11. Mousavinasab SM, Atai M, Salehi N, Salehi A. Effect of Shade and Light Curing Mode on the Degree of Conversion of Silorane-Based and Methacrylate-Based Resin Composites. JDent Biomater, 2016;3(4):299-305.

12. Bishara SE, Gordan VV, VonWald L, Jakobsen JR. Shear bond strength of composite, glass ionomer, and acidic primer adhesive systems. Am J Orthod Dentofacial Orthop. 1999;115(1):24-8. doi:10.1016/s0889-5406(99)70312-4

13. Reynolds I. A review of direct orthodontic bonding. Br J Orthod 1975;2(3):171-80 doi:https://doi.org/10.1080/0301228x.1975.11743666

14. Oztürk B, Malkoç S, Koyutürk AE, Catalbas B, Ozer F. Influence of different tooth types on the bond strength of two orthodontic adhesive systems. Eur JOrthod. 2008;30(4):407-12. doi:101093/ejo/cjn006 
15. Sfondrini MF,Cacciafesta V,Pistorio A, Sfondrini G. Effects of conventional and high-intensity light-curing on enamel shear bond strength of composite resin and resin-modified glass-ionomer. Am J Orthod Dentofacial Orthop. 2001;119(1):30-5. doi:10.1067/mod.2001.111399

16. Webster MJ,Nanda RS, Duncanson MG Jr,Khajotia SS, Sinha PK. The effect of saliva on shear bond strengths of hydrophilic bonding systems. Am J Orthod Dentofacial Orthop. 2001;119(1):54-8. doi:10.1067/mod.2001.109888

17. $0 z A A, 0 z A Z$, Arici S. In-vitro bond strengths and clinical failure rates of metal brackets bonded with different light-emitting diode units and curing times. Am J Orthod Dentofacial Orthop. 2016;149(2):212-6. doi:10.1016/j.ajodo.2015.07.036

18. Uşümez S, Büyükyilmaz T, Karaman Al. Effect of light-emitting diode on bond strength of orthodontic brackets. Angle Orthod. 2004;74(2):259-63. doi:10.1043/0003-3219(2004)074«0259:EOLDOB»20.C0;2

19. SenaLMF,Barbosa HAM, Caldas SGFR, Ozcan M, Souza ROAE. Effect of different bonding protocols on degree of monomer conversion and bond strength between orthodontic brackets and enamel. Braz Oral Res. 2018:32:e58. Published 2018 Jun 11. doi:10.1590/1807-3107bor-2018.vol32.0058

20. SharmaS, Tandon P, Nagar A, Singh GP, Singh A, Chugh VK. A comparison of shear bond strength of orthodontic brackets bonded with four different orthodontic adhesives. J Orthod Sci. 2014;3(2):29-33. doi:10.4103/22780203.132892

21. Almeida LF,Martins LP,Martins RP.Effects of reducing light-curing time of a high-power LED device on shear bond strength of brackets. J Orofac Orthop. 2018;79(5):352-8. doi:10.1007/s00056-018-0146-0

22. Faria-E-Silva AL, Covell DA Jr,Ferracane JL, Pfeifer CS. Effectiveness of high irradiance for short-time exposures on polymerization of composite under metal brackets. Angle Orthod. 2017;87(6):834-40. doi:10.2319/051817-338.1
23. Cerekja E,Cakirer B. Effect of short curing times with a high-intensity light-emitting diode or high-power halogen on shear bond strength of metal brackets before and after thermocycling. Angle 0rthod. 2011;:81(3):510-6. doi:10.2319/071810-412.1

24. Proffit WR, Fields Jr FH. Contemporary orthodontics contemporary fixed appliances. St.Louis:Mosby;2000. p. 385-417.

25. Shin DH, Rawls HR. Degree of conversion and color stability of the light curing resin with new photoinitiator systems. Dent Mater.2009;25(8):1030-8. doi:10.1016/j.dental.2009.03.004

26. Bang HC, Lim BS, Yoon TH, Lee YK, Kim CW. Effect of plasma arc curing on polymerization shrinkage of orthodontic adhesive resins. J Oral Rehabil. 2004;31(8):803-10. doi:10.1111/.j.1365-2842.2004.01301.x

27. Abedin F, Ye Q, Camarda K, Spencer P.Impact of light intensity on the polymerization kinetics and network structure of model hydrophobic and hydrophilic methacrylate based dental adhesive resin. J Biomed Mater ResB Appl Biomater.2016;104(8):1666-78. doi:10.1002/jbm.b.33517

28. Lovell LG, Newman SM, Bowman CN. The effects of light intensity, temperature, and comonomer composition on the polymerization behavior of dimethacrylate dental resins. J Dent Res. 1999;78(8):1469-76. doi:10.1177/0022 0345990780081301

29. Cerveira GP,Berthold TB, Souto AA, Spohr AM, Marchioro EM. Degree of conversion and hardness of an orthodontic resin cured with a light-emitting diode and a quartz-tungsten-halogen light. Eur J Orthod. 2010;32(1):83-6. doi:101093/ejo/cjp048

30. Albers HF. Tooth Color Restoratives. 9th ed. London:BCDecker Inc;2002

31. Souza R00, Michida SM, de Melo RM, Pavanelli CA, Bottino MA, Soares LE, et al. Conversion degree of indirect resin composites and effect of thermocycling on their physical properties. J Prosthodont.2010;19(3):218-25. doi:10.1111/j.1532849X.2009.00551.x

\section{Nuri Mert Topbaşı}

(Corresponding address)

Department of Orthodontics, Faculty of Dentistry, Biruni University, 10. Yll Caddesi

Protokol Yolu No: 4534010 Topkapı / İstanbul

E-mail: btopbasi@hotmail.com

Date submitted: 2020 Jan 30

Accept submission: 2020 May 06 